\title{
Call for Papers on a Special Issue:
}

\section{Clean Energy Development for Sustainable and Secure Cities}

\author{
Editors: Benjamin C. McLellan ${ }^{a^{*}}$, Hooman Farzaneh ${ }^{b}$ \\ ${ }^{a}$ Graduate School of Energy Science, Kyoto University \\ ${ }^{b}$ Department of Energy and Environmental Engineering, Kyushu University \\ Full paper submissions: 30 April, 2020 / Publication: 30 September, 2020
}

\section{Introduction to the Issue}

Cities are widely recognised as being critical to climate mitigation efforts due to their role as major demand centres for transport and energy. At the same time, the impacts of energy use in cities has many localised impacts, notably on air quality. Urbanisation is expected to continue increasing, while the conditions in cities will likely deteriorate with climate changes that are accentuated in urban environments.

Sustainable development of cities, including the economic, social and environmental development of urban systems and their supply chains, requires addressing the implications of energy supply. The transition to clean energy - from generation to usage - needs to be considered within the urban context, which offers both constraints and potential synergies.

Keywords: cities; co-benefits; clean energy; transport; electricity; heating; policy; projects; scenarios.

\section{Paper types and example topics}

Papers ranging from literature reviews of existing documents, to case studies, or novel research on long-term sustainability aspects are welcome. Topics of interest in this special issue include, but are not limited to:

- Literature reviews of policy approaches, models, regulatory frameworks, and other academic literature

- Case studies on clean energy project implementation or policies in cities

- Co-benefit evaluation of clean energy and climate mitigation projects and policies

- New energy vehicles and infrastructure in urban transport

- Lifecycle impacts of clean energy solutions in city

- Energy transitions in urban contexts

Importantly, submissions should include a discussion of how the research relates to sustainable development and considerations of human security.

\section{Important Dates}

Full Paper Deadline: 30 April, 2020

Full papers should be submitted via the online submission system.

Optional Abstract Pre-submission:

Authors considering submitting are encouraged to submit an abstract to the special issue editors by e-mail.

Ben McLellan: b-mclellan@energy.kyoto-u.ac.jp

Hooman Farzaneh: farzaneh.hooman.961@m.kyushu-u.ac.jp

Official publication of the issue: 30 September 2020.

Papers will be published online at the journal website. 


\section{Features of this special issue}

Professional, strict review: the manuscripts will all be reviewed by reputed scholars in the field of energy policy/management, or sustainability science.

Quick review: the editors will endeavour to provide a first review within one month of submission.

Open access: J-SustaiN is a free to publish, free to read journal. You are also free to upload a copy into any repository.

Instant online access: once accepted, each paper will be immediately uploaded onto the website of the journal, to ensure rapid access.

Website: http://www.j-sustain.com/ 